\title{
Epidemiology and Pathophysiology of Takotsubo Syndrome
}

Yoshihiro J. Akashi ${ }^{1}$, Holger M. Nef ${ }^{2}$, Alexander R. Lyon ${ }^{3,4}$

1 Division of Cardiology, Department of Internal Medicine, St. Marianna University School of Medicine, Kawasaki, Japan

2 Medizinische Klinik I, Kardiologie und Angiologie, Universitätsklinikum Gießen, Germany

3 National Heart and Lung Institute, Imperial College, London, UK

4 NIHR Cardiovascular Biomedical Research Unit, Royal Brompton Hospital, London, UK

Word count: 5303

All authors declare that the answer to the questions on your competing interest form are all No and therefore have nothing to declare

Address for correspondence:

Yoshihiro J. Akashi, MD, PhD.

Division of Cardiology, Department of Internal Medicine,

St. Marianna University School of Medicine

2-16-1 Sugao Miyamae-ku

Kawasaki-city, Kanagawa, 216-8511

Japan

Tel.: +81449778111

Fax: +8144976 7093

Email: yoakashi-circ@umin.ac.jp 


\section{Abstract}

Takotsubo syndrome is an acute cardiac syndrome first described in 1990 and characterized by transient left ventricular dysfunction affecting more than one coronary artery territory, and often in a circumferential apical, mid-ventricular or basal distribution. A number of pathophysiological explanations for this syndrome with its intriguing appearance have been proposed, and there is a growing awareness that these are not mutually exclusive, and that the reversible apical myocardial dysfunction observed could result from more than one pathophysiological phenomenon. The pathophysiology of takotsubo syndrome is complex, with integration of both neuroendocrine physiology involving the cognitive centres of the brain and hypothalamic-pituitary-adrenal axis, and the cardiovascular responses to the sudden sympathetic activation and surge in circulating catecholamines. The latter have been explored in detail, starting with the histological findings at biopsy, with the multiple morphological changes seen in the myocardium matching those seen after established catecholamine cardiotoxic effects. Clinically, both the acute prognosis and recurrence rate are unfortunately worse than previously reported. It is clear that the modern cardiology community has much still to learn regarding the epidemiology and the underlying pathophysiology of this fascinating condition in order to improve diagnostic and treatment pathways. 


\section{Key points}

Approximately $2 \%$ of all patients presenting to the hospitals with suspected acute coronary syndrome are usually identified with takotsubo syndrome. There is a predominance in post-menopausal women compared to men or younger women.

$\checkmark \quad$ Both the acute and long-term mortality are higher than previously recognized. The cumulative incidence of recurrence increased from $1.2 \%$ at first 6 months to nearly $5 \%$ at 6 years, and there is no current evidence to support treatment with any specific to prevent recurrence.

$\checkmark$ Systemic surges in catecholamines may cause vascular effects including acute coronary vasospasm and severe acute hypertension due to acute peripheral vasospasm followed by later peripheral vasodilation and hypotension. In the clinical setting, profound hypotension and cardiogenic shock is a common complication, however, it is not solely related to the extent of impairment of left ventricular (LV) systolic function, and thus probably relates in part to inappropriate peripheral vasodilation.

$\checkmark$ Biopsies during acute takotsubo syndrome are characterized by multiple morphological changes that are similar to those after catecholamine cardiotoxic effects supporting a direct effect in addition to the vascular influences.

$\checkmark$ The apical myocardium of the left ventricle has the highest density of $\beta$ adrenergic receptors ( $\beta A R)$, and is therefore most sensitive to circulating catecholamines.

$\checkmark$ High epinephrine levels result in a switch from the Gs stimulatory to the cardioinhibitory Gi secondary messenger pathway within the cardiomyocyte, which $\beta 2 A R$-Gi pathway activation is cardioprotective. However, this theory may not account for atypical anatomical variants of takotsubo syndrome. 


\section{Introduction}

In recent decades a novel cardiac syndrome with transient left ventricular dysfunction has been reported all over the world. This new entity has been referred to as "takotsubo cardiomyopathy" or "takotsubo syndrome", after the octopus fishing pot in Japanese, due to the particular shape and appearance of the left ventricle at endsystole observed with left ventriculography or echocardiography during the acute phase ${ }^{1}$. This syndrome has been classified as a primary and acquired cardiomyopathy according to the American Heart Association Scientific Statement ${ }^{2}$ and also classified as an unclassified cardiomyopathies according to the European Society of Cardiology Position Statement ${ }^{3}$; however whether it is a true cardiomyopathy remains to be determined - it can be considered clinically as an acute cardiac syndrome with reversible heart failure. This syndrome has been called various names in the medical literature including "takotsubo cardiomyopathy", "stress cardiomyopathy", "apical ballooning", and "broken heart syndrome" when triggered following bereavement. A mini epidemic occurred after the earthquakes in Christchurch, New Zealand in 2010 and in $2011^{4}$. US data have also shown small epidemics during the devastation caused by Hurricane Irene and during the worst tornado to hit the United States in 2011. This article primarily addresses the epidemiology and the currently discussed pathophysiological concepts of this novel cardiac syndrome.

\section{Epidemiology}

Diagnosis: Diagnostic criteria have been previously proposed from a few centres around the world (Table 1), and several diagnostic references have been proposed ${ }^{5-9}$. However, a worldwide consensus has not been fully established, but it is clear following the initial reports from Japan that this syndrome is observed throughout the 
world, and is not unique to Japanese population. The largest reported cohort data comes from the Nationwide Inpatient Sample (NIS) from the United States, based upon ICD-9 discharge coding. ${ }^{10}$ In 2008 the NIS analyzed 6,837 patients with takotsubo syndrome. It confirmed the previously recurrent trend from smaller cohorts that the condition most frequently affects postmenopausal women. Approximately $90 \%$ of the takotsubo syndrome patients in the NIS cohort were aged 50 years or more, $90 \%$ patients were female, and $70 \%$ patients were in the white ethnic group. Only $1 \%$ Asian patients were included in this large cohort, perhaps reflecting the demographic of patients in the hospitals providing data to the NIS. Across many different series, approximately $2 \%$ of all patients presenting to the hospitals with suspected acute coronary syndrome are usually identified with takotsubo syndrome ${ }^{6,11,12}$, with the postmenopausal female predominance described above ${ }^{13-16}$. If only female cases with suspected acute coronary syndrome are considered, up to $10 \%$ patients are ultimately diagnosed with takotsubo syndrome ${ }^{10}$. The initial NIS study demonstrated that approximately $0.02 \%$ of all hospitalizations $(6,837$ patients out of the $33,560,402$ patients with all diseases) were diagnosed as having takotsubo syndrome ${ }^{10}$, and subsequent reports from the same group suggest the incidence is approximately 100 new cases per million population per annum.

The evolution of diagnostic criteria reflect a change from a diagnosis of exclusion (apical bulge/no coronary disease) to a recognition that takotsubo syndrome has a number of characteristic features. For example is a condition of catecholaminestimulated myocardial stunning and on acute imaging may have evidence of inflammation. The detection of myocardial oedema in affected segments on cardiovascular magnetic resonance using T2STIR sequences helps to clarify this pathophysiology. The increasing recognition that takotsubo syndrome and bystander 
coronary disease may coexist also is important to remember, as not all patients with takotsubo syndrome have normal coronary arteries.

Emotional and/or physical stress frequently, but not always, precedes this syndrome. A range of typical stressors is listed in Table 2. They often reflect common stresses encountered in daily life, and it is perhaps not unsurprising that we encounter this syndrome so frequently now that it is recognised. A variety of non-cardiac acute diseases may also trigger takotsubo syndrome (see Table 2).

Takotsubo syndrome can be challenging to differentiate from acute coronary syndrome because many of its symptoms, clinical signs, echocardiographic and electrocardiographic findings are superficially similar to those in patients with acute coronary syndrome e.g. cardiac chest pain, ST elevation, regional wall motion abnormalities. Takotsubo syndrome is usually diagnosed by using coronary angiography depicting the absence of culprit coronary stenoses to explain the regional wall motion abnormalities which extend beyond a single coronary artery territory. Access to urgent invasive diagnostic coronary angiography is mandatory for patients presenting with acute chest pain and ST elevation. However if presentation is delayed (e.g. $>48$ hours, or pain free and stable at presentation), then CT coronary angiography may have a role as an alternative imaging investigation to exclude coronary stenosis in stable patients suspected of takotsubo syndrome ${ }^{17}$.

Electrocardiographic (ECG) abnormalities are usually present in patients with takotsubo syndrome ${ }^{18-26}$, i.e. ST-segment elevation acutely, and subsequently deep and widespread T-wave inversion; these changes evolve and depend on the time from the stress and symptom onset to clinical presentation and ECG recording. While 
several studies suggest criteria which can differentiate takotsubo syndrome from acute myocardial infarction, no clear criteria have been found to be highly sensitive and specific. The presence of ST elevation makes it challenging to distinguish from ST-elevated myocardial infarction, and access to emergency coronary angiography should not be delayed ${ }^{21-26}$. Kosuge et al. reported the differences in the distribution of ST-segment elevation between takotsubo syndrome and STEMI ${ }^{22}$. Most patients with anterior acute myocardial infarction have ST-segment elevation in leads V2 to V4. On the contrary, in patients with takotsubo syndrome, ST-segment elevation most frequently occurs in leads II, III, aVF, aVR and V5-6 facing the apical and inferolateral regions. The wall motion abnormalities in takotsubo syndrome less frequently extend to the V1-lead regions. Accordingly, typical takotsubo syndrome is distinguished from acute anterior myocardial infarction with the $90 \%$ or more sensitivity and specificity ${ }^{22}$. Various anatomical variants of takotsubo syndrome have been reported, including the classical apical variant, the midventricular variant and the basal or inverted variant ${ }^{11,15,16,27,28}$ To date there is no evidence for the usefulness of ECG in distinguishing the anatomical variants with diagnostic accuracy. The incidence of atypical anatomical variants (non-apical) in takotsubo syndrome is ranged from $8.4 \%$ to $40 \%{ }^{11,15,28}$; the prevalence of mid-ventricular type is at least $20 \%$, and that of basal type is about $3 \%$, so these are also not rare given the overall number of cases occurring.

In this syndrome, there is predominance in post-menopausal women than men or younger women previously described. Estrogen is thought to contrbute to the mechanism of this syndrome onset according to the results from the animal experiment ${ }^{29}$. Chronic estrogen supplimentation could partially attenuate the excess of cardiovascular response against stress ${ }^{30}$. However, no clinical trial regarding the 
estrogen replacement therapy for prevention in patients with takotsubo syndrome has been appeared. In case of men, this estrogen theory does not fit to explain, hence further studies are required to clarify the reason why post-menopausal women tend to occur.

\section{Prognosis}

Mortality: The prognosis of takotsubo syndrome was initially reported in a relatively favorable manner in comparison to STEMI ${ }^{31}$; however, subsequent studies have demonstrated that both the acute ${ }^{10}$ and long-term ${ }^{32,33}$ mortality are higher than previously recognized. Pre-hospital mortality is unknown and this should not be underestimated; the mortality during the acute phase in hospitalized patients is $\sim 4$ $5 \%$, and comparable with modern STEMI. Furthermore despite the recovery of LV function and absence of stenotic coronary artery disease, the mortality after hospital discharge is also remarkably poor and worse than an aged-matched healthy population. Intriguingly the prognosis is greatly influenced by non-cardiac diseases ${ }^{34}$, reflecting the many cases of secondary takotsubo syndrome, where the triggering medical condition may impart the poor prognosis ${ }^{14}$. Citro et al. reported that approximately $50 \%$ of cases of takotsubo syndrome in their Italian takotsubo registry aged 75 years or more had complications ${ }^{35}$. They also noted the complication rate was higher in patients $\geq 75$ years than those $<75$ years, and they revealed the higher in-hospital complication rate. This has been recently reinforced by similar findings from the German takotsubo registry ${ }^{36}$. In the largest published cohorts, the in-hospital mortality is $2.2 \%$ in Germany and Austria $^{37}, 2.6 \%$ in Italy ${ }^{38}, 4.2 \%$ in the U.S.A. ${ }^{39}$, $6.8 \%$ in $\operatorname{Japan}^{16}$, and $4.5 \%$ in the results obtained from the meta-analysis ${ }^{40}$. Japanese investigators have currently reported that the mortality is significantly different between the patients with 'in-hospital' versus 'out-of hospital' takotsubo 
syndrome, and in-hospital takotsubo syndrome was associated with the significantly higher in-hospital mortality due to the co-existing and triggering malignancy, chronic diseases, acute diseases, and infectious diseases ${ }^{16}$. The mortality in men appears to be higher based upon several different sources, albeit with relatively low patient numbers in these studies. Gender-related differences, including cardiogenic shock, cardiac arrest ${ }^{41}$ and mortality ${ }^{42}$, are more apparent for men than women. The existence of $\mathrm{J}$ wave on ECG in the acute phase is one potential marker of higher risk for ventricular tachyarrhythmia and sudden cardiac death ${ }^{45}$. Although the mechanical complications in takotsubo syndrome are not fully understood, they are clinical serious and carry a high mortality. Identification of clinical parameters predictive of mechanical complications, and understanding of the mechanism(s) underpinning them, will aid improvement of clinical treatment pathways.

Recurrence: The average recurrence rate reported ranges from 0-22\% depending upon the size of the series and duration of follow up (see table 3). Singh et al. reported that the annualized recurrent rate was about $1.5 \%{ }^{46}$ and the cumulative incidence of recurrence increased from $1.2 \%$ at first 6 months to nearly $5 \%$ at 6 years ${ }^{46}$. Even in the cases of recurrence, women still dominate this syndrome. In young patients aged less than 50 years, the median recurrence rate was perhaps surprisingly higher than those aged 50 or more years ${ }^{14}$. That may reflect a greater proportion of younger patients with secondary takotsubo syndrome where the triggering event is more likely to recur.

At the time of writing there is no evidence to support treatment with any specific to prevent recurrence. A recent meta-analysis supports this conclusion and reported the lack of efficacy of any therapy to prevent reccurence ${ }^{47}$. Recurrence has been reported in the context of $\beta$-blockers, which are perhaps the most logical 
pharmacological preventive strategy, given the stressful trigger and potential role of catecholamines.

\section{Pathophysiology}

\section{Based on histological finding}

From many clinical studies the hypothesis of excessive catecholamine as a trigger of the takotsubo syndrome has gained more and more attention. The temporal relationship between a stressful psychological event and the rapid onset of the clinical symptoms, and the number of cases triggered by iatrogenic catecholamine administration, support a significant link between catecholamines and the takotsubo syndrome. Nonetheless, there was never again such an extensive investigation of human biopsies in takotsubo syndrome in the acute phase and after functional recovery. Therefore, these descriptive results constitute of an inconceivable value for the understanding of this cardiac entity

\section{Insights from clinical histological studies}

Histological studies analyzing myocardial biopsies sampled during the acute phase, and at follow up, show that takotsubo syndrome is characterized by mulptiple morphological changes that are similar to those after catecholamine cardiotoxic effects. An electron microscopic analysis of the myocardium in patients with takotsubo syndrome showed a damage of contractile proteins with numerous vacuoles of different sizes and contents (myelin bodies, residual cellular products) leading to an enlargement of the diameter of the myocytes. Areas of non-specified cytoplasm and clusters of mitochondria with abnormalities in size and shape were observed. Contraction bands consistent with cytoplasmic calcium overload and fixed myofilament crossbridging were sporadically found. Cardiomyocyte nuclei were 
abnormal in appearance with altered size and location, typically at the border area of the cells. Cell swelling associated with damage of the basal lamina, but signs of necrosis and oncotic cell death associated with ischaemic injury were not detected. Interestingly, the acute catecholamine-induced changes in the composition and appearance of the myocardium with disarrangement of the cytoskeletal and contractile proteins was restored and reorganized after functional recovery. The theory of the direct myocardial toxicity due to catecholamines is further supported from the histopathological perspective. Typical structural changes as a result of catecholamine overload included a reversible intracellular arrangement ( $\alpha$ actinin, actin, titin) and a mild neutrophilic infiltration. The presence of myofibroblasts in the very early stage of the takotsubo syndrome might play a protective role by minimizing the observed myocardial disarray ${ }^{48}$. Significant enlargement of the extracellular matrix (ECM) staining positively for collagen-1 was found. This rapid alteration was mainly triggered by an increased ratio of collagen $\alpha-1$ (I) chain to collagen $\alpha-1$ (III) chain expression and deposition. These increased levels of fibrosis were also confirmed by fibronectin staining, and high norepinephrine or epinephrine levels might be a potential trigger for the observed high levels of profibrotic mediators (angiotensin II and free oxygen radicals). These and other factors lead to the activation of transforming growth factor $\beta$, stimulating connective tissue growth factor and the profibrotic osteopontin ${ }^{49}$. Nevertheless, the degree of fibrosis did not reach critical values therefore structural integrity was always maintained. One of the most striking observations in the biopsies for patients with takotsubo syndrome is the rapid regression of the abounded fibrosis. There is a significant increase of expression and proteolytic activity of matrix metalloproteinase-9 (MMP-9) in myocardial biopsies from patients during the acute episode of takotsubo syndrome. Proteolytic activity of MMPs, which are regulated by 
endogenous physiological inhibitors, leads to the degradation of several components of the ECM. Therefore, the balance between MMPs, tissue inhibitors of MMPs (TIMPs), and their regulators determines the progression of fibrosis in the heart. Accordingly, the significant reduction of TIMP-3 mRNA and protein levels during the recovery phase of the takotsubo syndrome causes disinhibition of MMP activity, which led to increased degradation of the ECM. This could explain the rapid regression and reduction in cardiac fibrosis in the takotsubo syndrome ${ }^{49}$. Molecular findings confirmed activation of the PI3K/AKT signaling pathway in takotsubo syndrome which might also contribute to a favorable outcome, by promoting cell survival and enhancing protein biosynthesis. Both factors are known to be essential for myocardial regeneration and improvement of left ventricular function ${ }^{50}$. In the acute phase of takotsubo syndrome, immunohistochemical staining for marcrophages (CD68) reveald the presence of several extracellular clusters. From many reports it is known that leukocyte count and C-reactive protein levels were mildly elevated. In the patients with takotsubo cardiomyopathy, injury of the cardiac myocytes pre- cedes infiltration of small round cells ${ }^{48}$. The main pathology of the autopsied hearts from the patients with takotsubo syndrome is summarized as myocardial injury and its sequelae, which resembled the findings of catecholamineinduced myocardial injury.

A number of investigators have additional documented marked elevation of natriuretic peptide levels at presentation in such patients. The extent of NT-proBNP/BNP levels, correlated with both the peak of catecholamine increase and the severity of LV systolic dysfunction. The value of BNP is significantly higher in takotsubo syndrom than in acute myocardial infarction. Early BNP/TnT and BNP/CKMB ratios help to 
differentiate the takotsubo syndrome from acute myocardial infarction with greater accuracy than BNP alone ${ }^{51}$.

\section{Catecholamine-mediated alteration of calcium-regulatory proteins}

The stimulation of $\beta$-adrenoceptors ( $\beta$ ARs) by supraphysiological levels of catecholamines leads to an alteration of the calcium-regulated proteins in takotsubo syndrome. The homologous intrinsic membrane proteins Sarcolipin (SLN) and Phospholamban (PLN), which are confined to the sarcoplasmic reticulum (SR), are critical regulators of cardiac contractility ${ }^{52}$. An unusually elevated ventricular expression of SLN is observed in acute takotsubo syndrome. SLN negatively regulates the sarcoplasmic/endoplasmic reticulum calcium ATPase 2 (SERCA2) by lowering its affinity for calcium. SLN is located in the same SR membrane subcompartments as PLN, inducing a super-inhibitory effect on the SERCA pump. PLN, which is also a main regulator of SERCA activity, is also significantly upregulated during the acute phase. Perhaps paradoxically in the aftermath of intense $\beta A R$ activation, the PKA-dependent and CamKII-dependent phosphorylation pathways are altered leading to a dephosphorylation particularly of the PLN Ser-16 and the PLN Thr-17, further increasing the inhibitory effect upon SERCA2a ${ }^{53}$. Immunohistochemistry studies showed that the fluorescence intensity of PLN-Ser16 was lower in biopsies taken from the acute phase compared with healthy myocardium.

Although, there is no direct evidence that the reported alterations in the expression of calcium-regulatory proteins are responsible for the acute detrimental effects of takotsubo syndrome early results suggest that intense G-protein-stimulated $\beta 1$-AR signaling can directly modulate gene expression via the cyclic AMP-responsive 
element binding protein 1 and calcineurin-nuclear factor of activated T cells (NFAT) signaling pathways ${ }^{54}$.

\section{Stress hormone-induced disturbance of microcirculation}

An increase of extracellular fibrosis is usually associated with disturbed microcirculation. In takotsubo syndrome a significant reduction in capillary density was documented. Endomyocardial capillaries were visualized by

immunohistochemical staining for $C D 31^{48,49}$. This was mainly due to the expansion of the ECM, which then led to a relative decrease in the supplying capillaries. This ultimately results in a mismatch between oxygen supply and demand in cardiomyocytes. In a recent study, ultrastructural analyses of myocardial tissue clearly showed intracellular vacuoles and intracellular accumulation of ubiquitin in the acute takotsubo syndrome ${ }^{48}$. These results indicate a potential oxygen deficiency contributing to cardiomyocyte dysfunction.

\section{The central role of catecholamines}

The pathophysiology of takotsubo syndrome is complex and reflects the integrated cardiovascular responses to sudden surges in endogenous, or exogenously administered, catecholamines, often in the context of acute severe stress. There are also several clinical conditions, including acute subarachnoid haemorrhage, phaeochromocytoma and acute thyrotoxicosis, which are associated with acute severe sympathetic neural activation or adrenal catecholamine release which can trigger takotsubo syndrome. Many observational clinical studies, and a few laboratory models, have helped to provide the current basis for several pathophysiological hypotheses. The role of catecholamines appears central to the pathophysiology of takotsubo syndrome, and catecholamines have multiple direct and indirect effects on 
the brain, systemic vasculature, coronary vasculature and myocardium which may be relevant.

The pathophysiology can be broadly considered in two phases. The first starts with the cognitive centres of the brain and hypothalamic-pituitary-adrenal (HPA) axis, and how much epinephrine and norepinephrine are released in response to a given stress i.e. the 'gain' of the hypothalamic-pituitary-adrenal axis. Serum catecholamine levels in patients with takotsubo syndrome at presentation are significantly elevated compared both to resting levels in the same patient and to levels in comparable patients with acute heart failure secondary to acute myocardial infarction, suggesting the potential for excessive HPA gain and epinephrine release in susceptible individuals ${ }^{55}$. This is most relevant for takotsubo syndrome cases triggered by emotional stress. The thresholds for stress tolerance, and HPA gain, are incompletely understood, but there is supporting evidence that this may be important in some cases. The incidence of stress and anxiety disorder is higher in cohorts of Takotsubo syndrome patients compared to control emergency populations ${ }^{10}$. This may reflect a risk or predisposition rather than the sole causative issue. It is well established that there are higher resting levels of catecholamines in individuals with panic disorder, contributing to their clinical syndrome, and it is plausible that these individuals are predisposed to a higher norepinephrine and epinephrine surge for a given stress ${ }^{56}$. A recent study of the circulating microRNA profile of takotsubo syndrome patients showed striking difference compared to the control group of STEMI ${ }^{57}$. In particular, there was the higher levels of miR16 and miR26a which has been associated with neuropsychiatric disease. In summary in some individuals with takotsubo syndrome there may be pre-existing anxiety disorder phenotype, and identification may lead to appropriate treatment strategies in order to aid management strategies for future stressful episodes. 
The second is the cardiovascular response to the sudden sympathetic activation and surge in circulating catecholamines. A number of hypotheses have been proposed to explain takotsubo syndrome and the cardiac response to severe stress. The three predominant hypotheses are reviewed below, and whilst these have been proposed in isolation, it is becoming increasingly apparent that they may not be mutually exclusive given the entire cardiovascular system is exposed to the same 'catecholamine storm'. The potential for combinations of multivessel vasospasm, increased ventricular afterload from the surge of systemic vasoconstriction and arterial hypertension, and the impact of the high catecholamines directly upto the myocardium dictated by $\beta A R$ gradients may contribute to yield a final common endpoint of acute apical dysfunction (see Figure 2). Taking an integrated approach may be a path to understand the diverse range of experimental and clinical observations reported. For example, it is plausible that multivessel vasospasm and catecholaminergic myocardial stunning may co-exist, with the latter modifying the myocardial response to ischaemic via activation of cardioprotective signalling pathways. These are evident in the preclinical models and in the biopsy specimens from patients during the acute phase (see above). Concomitant vasospasm, driven by high norepinephrine and epinephrine levels via $\alpha$-adrenoceptors in the vasculature, and myocardial stunning via $\beta A R$ signalling, is highly likely given the systemic activation and surges in catecholamines. The impact of peripheral vascular responses with vasoconstriction, systemic arterial hypertension and elevated afterload, versus vasodilatation, hypotension and reduced afterload, may also be relevant in determining both the anatomical variant (see below), and the susceptibility to various complications such as acute left ventricular outflow tract obstruction, which may further exacerbate the developing acute failure syndrome. 


\section{Acute multivessel coronary spasm}

Many of the initial Japanese takotsubo syndrome cases described had multivessel vasospasm at diagnostic coronary angiography, and it is conceivable that a number of individuals may be prone to stress-induced multivessel coronary artery spasm. In subsequent series the incidence of vasospasm has been variable, but spontaneous vasospasm is observed in $\sim 5-10 \%$ cases. Vasospastic provocation has been studied during the acute phase, with evidence in $10-43 \%$ patients in various series ${ }^{58,59}$. In non-Japanese populations, especially when performed in the convalescent phase or later, epicardial coronary vasospasm is not a common finding, whereas microvascular dysfunction was more common ${ }^{60}$. A review of 9 cohort studies concluded provocation-induced vasospasm was present in 34 of 123 patients studied $(27.6 \%)^{61}$. One group report that the inducible vasospasm with acetylcholine provocation at follow up lead to recapitulation of the acute apical dysfunction, supportive of the potential role of multivessel vasospasm, at least in some cases of the apical variant ${ }^{62}$. Further studies suggest endothelin levels may be higher in patients with acute takotsubo syndrome ${ }^{57}$. Endothelin is an extremely potent vasoconstrictor, and could be a potential mechanism to trigger multivessel vasospasm. In addition after any stress and high surge in catecholamines, generalised impairment of endothelial function secondary to oxidative stress is to be expected, and both coronary and peripheral arteries may be prone to vasospasm upon provocation. The distinction between cause and association is important to distinguish before all cases of Takotsubo syndrome can be explained by multivessel vasospasm. However whilst in some cases vasospasm correlates with the region of dysfunction, equally in other cases it did not, leading some authors to conclude that vasospasm plays no role in the aetiology of takotsubo syndrome ${ }^{63}$. Anatomical abnormalities regarding coronary arteries have also been observed in patients with 
takotsubo syndrome, i.e. myocardial bridging ${ }^{64}$ and hypoplastis coronary arteries ${ }^{65}$, but there is no evidence to suppot a causative role.

A number of clinical cases reported were triggered by either dobutamine ${ }^{66}$, a vasodilator with minimal vasospastic effects, or epinephrine, which also has a dominant coronary vasodilatory effect, and therefore would not support vasospasm as the primary mediator. Likewise in preclinical models high doses of the $\beta A R$ agonist isoproterenol can trigger acute apical dysfunction, supporting the hypothesis that vasospasm is not essential for an acute takotsubo phenotype. These studies have also shown normal myocardial perfusion when studied using bubble-contrast echocardiography during the development of apical dysfunction following isoproterenol injection ${ }^{67}$. There are also significant differences in histopathological features with endomyocardial biopsies taken from patients with takotsubo syndrome showing a pattern of myocardial abnormalities not associated with infarcted, stunned, or hibernating myocardium, which would not support a primary vascular cause (see above $)^{48}$.

\section{Direct catecholamine-mediated myocardial stunning}

A number of different groups have suggested that the surge of high circulating catecholamine levels may have a direct effect upon the ventricular myocardium which can cause the apical ballooning pattern observed. Several years ago one of the authors (ARL) proposed a hypothesis in this journal which could explain the anatomical pattern of myocardial dysfunction in acute takotsubo syndrome ${ }^{68}$. The B2AR hypothesis reflects the repeated observation of apical-basal gradients of sympathetic nerve endings and $\beta A R s$ in mammalian hearts ${ }^{68}$. A consistent finding across several mammalian species, including humans, is a higher sympathetic nerve 
density in the basal myocardium compared to the ape ${ }^{69}$. Therefore the location of cardiac sympathetic nerve terminals does not explain apical hypokinesia, the most common anatomical variant, although they may have a role in the basal or inverted takotsubo variant. In contrast, the apical myocardium of the left ventricle has the highest density of $\beta A R s$ in several studies of non-human mammalian hearts, and is therefore most sensitive to circulating catecholamines including exogenous catecholamine administration ${ }^{70-72}$, although this remains to be clarified in human hearts. These opposing apical-basal sympathetic nerve and $\beta A R$ gradients allow balanced myocardial responses to sympathetic activation under normal levels of sympathetic activation, for example during exercise or mild stresses. However at the highest levels of circulating epinephrine, released systemically from the adrenal glands in the context of extreme stress, the $\beta A R$ receptor gradient would determine the dominant response within the ventricular myocardium.

Whereas epinephrine is generally viewed as a positive inotrope, this is only the case at low and medium concentrations. Several studies demonstrate that it has a bellshaped dose-response relationship for myocardial contraction, and at the highest doses epinephrine is a negative inotrope via the $\beta 2 A R^{73,74}$. This is a pharmacological property of the $\beta A R$ known as stimulus trafficking, where high epinephrine levels result in a switch from the Gs stimulatory to the cardioinhibitory Gi secondary messenger pathway within the cardiomyocyte ${ }^{68,73}$. $\beta 2 A R-G i$ pathway activation is cardioprotective via activation of a number of antiapoptotic pathways ${ }^{75}$ and this may minimise the toxic effects of vasospastic ischaemia, pressure-induced injury from high intracavity pressures, and the excessive catecholaminergic stimulation upon the myocardium. It is important to note that whilst $\beta 2 A R-G i$ signalling has been demonstrated in human hearts with chronic heart failure, it has yet to be confirmed in human hearts during acute takotsubo syndrome. Activation of these patways is noted 
in the moyocardial biospies from takotsubo syndrome patients during the acute phase as noted above. This hypothesis was tested in a rat takotsubo model where high dose epinephrine-induced reversible apical hypokinesia, and this takotsubo model could be prevented by pretreatment with the Gi protein inhibitor pertussis toxin $^{72}$. This observation was replicated in another preclinical model where pertussis toxin prevented acute apical dysfunction induced by high dose isoproterenol injection, albeit with a high mortality in the pertussis toxin treated group ${ }^{76}$. Recently computer modelling studies evaluated the impact of varying $\beta A R$ gradients across the left ventricle under different haemodynamic situations and could replicate the acute apical dysfunction observed when the $\beta A R$ density was highest at the apex ${ }^{77}$.

\section{Excessive transient ventricular afterload and takotsubo variants}

The peripheral circulatory and systemic responses to an acute catecholamine administration are dramatic, whether observed clinically or in the research laboratory. In the rat epinephrine model, within seconds of intravenous epinephrine injection there is severe peripheral vasoconstriction causing a surge or both systolic and diastolic hypertension ${ }^{72}$. Peak systolic pressure was initially $>250 \mathrm{mmHg}$, with diastolic pressure $>100 \mathrm{mmHg}$, activating the vagal reflex and sinus bradycardia ${ }^{72}$. This severe acute arterial hypertension lasts only a few minutes, and during this hyperacute phase the heart has a hypercontractile state. This finding has been recently confirmed in a case report where the authors found that during the hyperacute phase of takotsubo syndrome there was a hypertensive crisis associated mainly with basal hyperkinesis ${ }^{78}$, and hypertensive crises are frequently observed in patients with subarachnoid haemorrhage and phaeochromocytoma. The physiological state evolves into a secondary phase with developing acute apical dysfunction, normotension or hypotension, frequently complicated by cardiogenic 
shock, and either persisting vasoconstriction or paradoxical vasodilation given the impaired cardiac function.

Considering these temporal phases is important when interpreting the clinical and preclinical observations and the role of haemodynamics and ventricular-arterial coupling, and has recently been reviewed ${ }^{79}$. The wall stress imparted by the high intracavity pressures may initiate regional dysfunction. The potential for the hypertensive storm to cause acute myocardial dysfunction has been explored using a variety of catecholamines with some intriguing findings ${ }^{80}$. Administration of primary vasoconstrictors, causing high afterload, frequently triggered the inverted or basal takotsubo variant. One might expect them to trigger coronary vasospasm and apical dysfunction, but this was not the case in this reported study. In contrast catecholamines which reduce peripheral vascular resistance via vasodilation, with lower systolic blood pressure and ventricular afterload, were more likely to cause the typical apical variant ${ }^{78}$. This is interesting as some patients have systemic arterial vasodilatation and low systemic vascular resistance, which may reflect maladaptive regulation by the peripheral sympathetic nervous system ${ }^{33,81}$. This is usually measured hours after the initial stressful trigger and catecholamine surge, and so whether it is present immediately during the acute stress remains to be clarified. It is clear that there are abnormalities of peripheral sympathetic nerve function and arterial vasomotor regulation in the aftermath of the acute catecholamine storm ${ }^{33,80 \text { - }}$ 82. These vasodilating catecholamines may also activate myocardial $\beta 2 A R s$ in addition to vascular $\beta 2 A R s$, and therefore this may reflect a mixed effect.

It is conceivable that the multiple factors altering myocardial physiology, including the acutely elevated, afterload insult and ischaemia from coronary vasospasm in the immediate seconds and minutes after the surge in endogenous catecholamines, followed by the subsequent reduction in contractile responses due of $\beta 2-\mathrm{Gi}$ signalling 
and activation of cardioprotective pathways, may occur in concert resulting in the clinical pattern of apical dysfunction observed. Some individuals may be more susceptible to one pathophysiological mechanism which could dominate. For example one study reported that individuals with takotsubo syndrome carried the GRK5L41Q polymorphism which is a gain-of-function polymorphism for the GRK5 enzyme $^{83}$. The GRK5 kinase phosphorylates $\beta 2 A R$ and activates stimulus trafficking. Therefore individuals harbouring this polymorphism may developed negative inotropic responses to epinephrine at lower levels, and may also have greater vasodilatory responses ${ }^{84}$. The two in combination would potentially lower the threshold for inducing apical dysfunction in the context of acute stress. However other genetic studies have failed to replicate this finding ${ }^{85}$, and therefore this may reflect a susceptibility genetic effect rather than absolute cause.

\section{Post-menopausal hormonal status and catecholaminergic responses}

Given the central role of catecholamines and the strong predisposition for occurrence in postmenopausal women, the potential role of chronic oestrogen exposure, and loss of the sympatholytic effects of oestrogens, should be considered. It is well established that oestrogens reduced the inotropic and chronotropic responses to catecholamines, alter vascular reactivity and are cardioprotective ${ }^{86-88}$. Several studies demonstrate that myocardial $\beta A R$-mediated positive inotropic responses are greater in male hearts than matched female hearts, and these differences are mediated by a lower level of $\beta 1 A R$-signalling. The reduced myocardial $\beta 1 A R$-signalling in ovulating females appears protective from myocardial insults including high catecholamines from stress stimuli as well as ischaemia-reperfusion injury ${ }^{29,}{ }^{89}$. Oophrectomy removes this protective effect in preclinical models, and is associated with an increase in $\beta 1 A R-s i g n a l l i n g$ and inotropy. In a specific model of stress-induced 
takotsubo syndrome by conscious restraint, oestrogen supplementation to oophrectomised animals reduced the apical dysfunction observed during stress ${ }^{30,86}$. Oestrogens also increase vascular $\beta 2 A R$-mediated vasoreactivity, and their loss following menopause could lead to greater vasoconstriction with reduced B2ARmediated vasodilatation in the setting of high stress-induced surges in catecholamines.

More research is required to help clarify the particular role of each of the hypotheses discussed, in order to further understand the cardiovascular responses to acute stress, and the pathophysiology underpinning takotsubo syndrome.

\section{Conclusion}

Takotsubo syndrome is an acute cardiac syndrome first described in 1990 and characterized by transient left ventricular dysfunction affecting more than one coronary artery territory, and often in a circumferential apical, mid-ventricular or basal distribution. Currently there is a growing awareness that these are not mutually exclusive and that the reversible apical myocardial dysfunction observed could result from more than one pathophysiological phenomenon. It is clear that the modern cardiology community has much still to learn regarding the epidemiology and the underlying pathophysiology of this fascinating condition in order to improve diagnostic and treatment pathways. 


\section{REFERENCES}

1. Dote, K., Sato, H., Tateishi, H., Uchida, T. \& Ishihara, M. [Myocardial stunning due to simultaneous multivessel coronary spasms: a review of 5 cases]. $J$ Cardiol 21, 203-14 (1991).

2. Maron, B.J. et al. Contemporary definitions and classification of the cardiomyopathies: an American Heart Association Scientific Statement from the Council on Clinical Cardiology, Heart Failure and Transplantation Committee; Quality of Care and Outcomes Research and Functional Genomics and Translational Biology Interdisciplinary Working Groups; and Council on Epidemiology and Prevention. Circulation 113, 1807-16 (2006).

3. Elliott, P. et al. Classification of the cardiomyopathies: a position statement from the European Society Of Cardiology Working Group on Myocardial and Pericardial Diseases. Eur Heart J 29, 270-6 (2008).

4. Chan, C. et al. Acute myocardial infarction and stress cardiomyopathy following the Christchurch earthquakes. PLoS One 8, e68504 (2013).

5. Kawai, S., Kitabatake, A. \& Tomoike, H. Guidelines for diagnosis of takotsubo (ampulla) cardiomyopathy. Circ J 71, 990-2 (2007).

6. Prasad, A., Lerman, A. \& Rihal, C.S. Apical ballooning syndrome (Tako-Tsubo or stress cardiomyopathy): a mimic of acute myocardial infarction. Am Heart $J$ 155, 408-17 (2008).

7. Omerovic, E. How to think about stress-induced cardiomyopathy?--Think "out of the box"! Scand Cardiovasc J 45, 67-71 (2011).

8. Eitel, I. et al. Clinical characteristics and cardiovascular magnetic resonance findings in stress (takotsubo) cardiomyopathy. JAMA 306, 277-86 (2011).

9. Parodi, G. et al. Revised clinical diagnostic criteria for Tako-tsubo syndrome: the Tako-tsubo Italian Network proposal. Int J Cardiol 172, 282-3 (2014).

10. Deshmukh, A. et al. Prevalence of Takotsubo cardiomyopathy in the United States. Am Heart J 164, 66-71 e1 (2012).

11. Kurowski, V. et al. Apical and midventricular transient left ventricular dysfunction syndrome (tako-tsubo cardiomyopathy): frequency, mechanisms, and prognosis. Chest 132, 809-16 (2007).

12. Akashi, Y.J., Goldstein, D.S., Barbaro, G. \& Ueyama, T. Takotsubo cardiomyopathy: a new form of acute, reversible heart failure. Circulation 118, 2754-62 (2008).

13. Primetshofer, D., Agladze, R., Kratzer, H., Reisinger, J. \& Siostrzonek, P. Tako-Tsubo syndrome: an important differential diagnosis in patients with acute chest pain. Wien Klin Wochenschr 122, 37-44 (2010).

14. Patel, S.M., Chokka, R.G., Prasad, K. \& Prasad, A. Distinctive clinical characteristics according to age and gender in apical ballooning syndrome (takotsubo/stress cardiomyopathy): an analysis focusing on men and young women. J Card Fail 19, 306-10 (2013).

15. Murakami, T. et al. Characterization of predictors of in-hospital cardiac complications of takotsubo cardiomyopathy: multi-center registry from Tokyo CCU Network. J Cardio/ 63, 269-73 (2014).

16. Isogai, T. et al. Out-of-hospital versus in-hospital Takotsubo cardiomyopathy: Analysis of 3719 patients in the Diagnosis Procedure Combination database in Japan. Int J Cardiol 176, 413-7 (2014). 
17. Otalvaro, L., Zambrano, J.P. \& Fishman, J.E. Takotsubo cardiomyopathy: utility of cardiac computed tomography angiography for acute diagnosis. $J$ Thorac Imaging 26, W83-5 (2011).

18. Ogura, R. et al. Specific findings of the standard 12-lead ECG in patients with 'Takotsubo' cardiomyopathy: comparison with the findings of acute anterior myocardial infarction. Circ J 67, 687-690 (2003).

19. Kurisu, S. et al. Time course of electrocardiographic changes in patients with tako-tsubo syndrome: comparison with acute myocardial infarction with minimal enzymatic release. Circ J 68, 77-81 (2004).

20. Mitsuma, W. et al. Serial electrocardiographic findings in women with Takotsubo cardiomyopathy. Am J Cardiol 100, 106-9 (2007).

21. Dib, C. et al. Clinical correlates and prognostic significance of electrocardiographic abnormalities in apical ballooning syndrome (Takotsubo/stress-induced cardiomyopathy). Am Heart J 157, 933-8 (2009).

22. Kosuge, M. et al. Simple and accurate electrocardiographic criteria to differentiate takotsubo cardiomyopathy from anterior acute myocardial infarction. J Am Coll Cardiol 55, 2514-6 (2010).

23. Tamura, A. et al. A new electrocardiographic criterion to differentiate between Takotsubo cardiomyopathy and anterior wall ST-segment elevation acute myocardial infarction. Am J Cardiol 108, 630-3 (2011).

24. Takashio, S. et al. Usefulness of SUM of ST-segment elevation on electrocardiograms (limb leads) for predicting in-hospital complications in patients with stress (takotsubo) cardiomyopathy. Am J Cardiol 109, 1651-6 (2012).

25. Kosuge, M. \& Kimura, K. Electrocardiographic findings of takotsubo cardiomyopathy as compared with those of anterior acute myocardial infarction. J Electrocardiol 47, 684-9 (2014).

26. Johnson, N.P., Chavez, J.F., Mosley, W.J., 2nd, Flaherty, J.D. \& Fox, J.M. Performance of electrocardiographic criteria to differentiate Takotsubo cardiomyopathy from acute anterior ST elevation myocardial infarction. Int $J$ Cardiol 164, 345-8 (2013).

27. Jabara, R. et al. Comparison of the clinical characteristics of apical and nonapical variants of "broken heart" (takotsubo) syndrome in the United States. $J$ Invasive Cardiol 21, 216-22 (2009).

28. Nishida, J. et al. "Ballooning" patterns in takotsubo cardiomyopathy reflect different clinical backgrounds and outcomes: a BOREAS-TCM study. Heart Vessels (2014).

29. Ueyama, T. et al. Estrogen attenuates the emotional stress-induced cardiac responses in the animal model of Tako-tsubo (Ampulla) cardiomyopathy. $J$ Cardiovasc Pharmacol 42 Suppl 1, S117-9 (2003).

30. Ueyama, T. et al. Chronic estrogen supplementation following ovariectomy improves the emotional stress-induced cardiovascular responses by indirect action on the nervous system and by direct action on the heart. Circ J 71, 56573 (2007).

31. Elesber, A.A. et al. Four-year recurrence rate and prognosis of the apical ballooning syndrome. J Am Coll Cardiol 50, 448-52 (2007).

32. Sharkey, S.W. et al. Natural history and expansive clinical profile of stress (tako-tsubo) cardiomyopathy. J Am Coll Cardiol 55, 333-41 (2010).

33. Schultz, T. et al. Stress-induced cardiomyopathy in Sweden: evidence for different ethnic predisposition and altered cardio-circulatory status. Cardiology 122, 180-6 (2012). 
34. Song, B.G. et al. Clinical characteristics, ballooning pattern, and long-term prognosis of transient left ventricular ballooning syndrome. Heart Lung 39, 188-95 (2010).

35. Citro, R. et al. Differences in clinical features and in-hospital outcomes of older adults with tako-tsubo cardiomyopathy. J Am Geriatr Soc 60, 93-8 (2012).

36. Schneider, B. et al. Complications in the clinical course of tako-tsubo cardiomyopathy. Int J Cardiol 176, 199-205 (2014).

37. Schneider, B. et al. Gender differences in the manifestation of tako-tsubo cardiomyopathy. Int J Cardiol 166, 584-8 (2013).

38. Citro, R. et al. Echocardiographic correlates of acute heart failure, cardiogenic shock, and in-hospital mortality in tako-tsubo cardiomyopathy. JACC Cardiovasc Imaging 7, 119-29 (2014).

39. Brinjikji, W., El-Sayed, A.M. \& Salka, S. In-hospital mortality among patients with takotsubo cardiomyopathy: A study of the National Inpatient Sample 2008 to 2009. Am Heart J 164, 215-221 (2012).

40. Singh, K. et al. Meta-analysis of clinical correlates of acute mortality in takotsubo cardiomyopathy. Am J Cardiol 113, 1420-8 (2014).

41. Schneider, B., Athanasiadis, A. \& Sechtem, U. Gender-related differences in takotsubo cardiomyopathy. Heart Fail Clin 9, 137-46, vii (2013).

42. Vriz, O. et al. Tako-tsubo cardiomyopathy: insights from a community hospital. J Cardiovasc Med (Hagerstown) 14, 576-81 (2013).

43. Lee, P.H. et al. Outcomes of patients with stress-induced cardiomyopathy diagnosed by echocardiography in a tertiary referral hospital. J Am Soc Echocardiogr 23, 766-71 (2010).

44. Previtali, M. et al. Clinical characteristics and outcome of left ventricular ballooning syndrome in a European population. Am J Cardiol 107, 120-5 (2011).

45. Shimizu, M. et al. J wave and fragmented QRS formation during the hyperacute phase in Takotsubo cardiomyopathy. Circ J 78, 943-9 (2014).

46. Singh, K. et al. Systematic review and meta-analysis of incidence and correlates of recurrence of takotsubo cardiomyopathy. Int J Cardiol 174, 696701 (2014).

47. Santoro, F. et al. Lack of efficacy of drug therapy in preventing takotsubo cardiomyopathy recurrence: a meta-analysis. Clin Cardiol 37, 434-9 (2014).

48. Nef, H.M. et al. Tako-Tsubo cardiomyopathy: intraindividual structural analysis in the acute phase and after functional recovery. Eur Heart J 28, 2456-64 (2007).

49. Szardien, S. et al. Molecular basis of disturbed extracellular matrix homeostasis in stress cardiomyopathy. Int J Cardiol 168, 1685-8 (2013).

50. Nef, H.M. et al. Activated cell survival cascade protects cardiomyocytes from cell death in Tako-Tsubo cardiomyopathy. Eur J Heart Fail 11, 758-64 (2009).

51. Randhawa, M.S., Dhillon, A.S., Taylor, H.C., Sun, Z. \& Desai, M.Y. Diagnostic utility of cardiac biomarkers in discriminating Takotsubo cardiomyopathy from acute myocardial infarction. J Card Fail 20, 377 e25-31 (2014).

52. Nef, H.M. et al. Expression profiling of cardiac genes in Tako-Tsubo cardiomyopathy: insight into a new cardiac entity. J Mol Cell Cardiol 44, 395404 (2008).

53. Nef, H.M. et al. Reduced sarcoplasmic reticulum $\mathrm{Ca}(2+)$-ATPase activity and dephosphorylated phospholamban contribute to contractile dysfunction in human hibernating myocardium. Mol Cell Biochem 282, 53-63 (2006). 
54. Nef, H.M., Mollmann, H., Akashi, Y.J. \& Hamm, C.W. Mechanisms of stress (Takotsubo) cardiomyopathy. Nat Rev Cardiol 7, 187-93 (2010).

55. Wittstein, I.S. et al. Neurohumoral Features of Myocardial Stunning Due to Sudden Emotional Stress. N Engl J Med 352, 539-48 (2005).

56. Wilkinson, D.J. et al. Sympathetic activity in patients with panic disorder at rest, under laboratory mental stress, and during panic attacks. Arch Gen Psychiatry 55, 511-20 (1998).

57. Jaguszewski, M. et al. A signature of circulating microRNAs differentiates takotsubo cardiomyopathy from acute myocardial infarction. Eur Heart J 35, 999-1006 (2014).

58. Kurisu, S. et al. Tako-tsubo-like left ventricular dysfunction with ST-segment elevation: a novel cardiac syndrome mimicking acute myocardial infarction. Am Heart J 143, 448-55 (2002).

59. Tsuchihashi, K. et al. Transient left ventricular apical ballooning without coronary artery stenosis: a novel heart syndrome mimicking acute myocardial infarction. Angina Pectoris-Myocardial Infarction Investigations in Japan. J Am Coll Cardio/ 38, 11-8 (2001).

60. Patel, S.M., Lerman, A., Lennon, R.J. \& Prasad, A. Impaired coronary microvascular reactivity in women with apical ballooning syndrome (Takotsubo/stress cardiomyopathy). Eur Heart J Acute Cardiovasc Care 2, 147-52 (2013).

61. Pilgrim, T.M. \& Wyss, T.R. Takotsubo cardiomyopathy or transient left ventricular apical ballooning syndrome: A systematic review. Int J Cardiol 124, 283-92 (2008).

62. Angelini, P. Transient left ventricular apical ballooning: A unifying pathophysiologic theory at the edge of Prinzmetal angina. Catheter Cardiovasc Interv 71, 342-52 (2008).

63. Abe, Y. et al. Assessment of clinical features in transient left ventricular apical ballooning. J Am Coll Cardiol 41, 737-42 (2003).

64. Stiermaier, T. et al. Frequency and significance of myocardial bridging and recurrent segment of the left anterior descending coronary artery in patients with takotsubo cardiomyopathy. Am J Cardiol 114, 1204-9 (2014).

65. Cocco, G. \& Chu, D. Stress-induced cardiomyopathy: A review. Eur J Intern Med 18, 369-79 (2007).

66. Abraham, J. et al. Stress cardiomyopathy after intravenous administration of catecholamines and beta-receptor agonists. J Am Coll Cardiol 53, 1320-5 (2009).

67. Redfors, B. et al. Contrast echocardiography reveals apparently normal coronary perfusion in a rat model of stress-induced (Takotsubo) cardiomyopathy. Eur Heart J Cardiovasc Imaging 15, 152-7 (2014).

68. Lyon, A.R., Rees, P.S., Prasad, S., Poole-Wilson, P.A. \& Harding, S.E. Stress (Takotsubo) cardiomyopathy-a novel pathophysiological hypothesis to explain catecholamine-induced acute myocardial stunning. Nat Clin Pract Cardiovasc Med 5, 22-29 (2008).

69. Kawano, H., Okada, R. \& Yano, K. Histological study on the distribution of autonomic nerves in the human heart. Heart Vessels 18, 32-9 (2003).

70. Mori, H. et al. Increased responsiveness of left ventricular apical myocardium to adrenergic stimuli. Cardiovasc Res 27, 192-8 (1993).

71. Brouri, F. et al. Blockade of beta 1- and desensitization of beta 2adrenoceptors reduce isoprenaline-induced cardiac fibrosis. Eur $\mathrm{J}$ Pharmacol 485, 227-34 (2004). 
72. Paur, H. et al. High Levels of Circulating Epinephrine Trigger Apical Cardiodepression in a beta2-Adrenergic Receptor/Gi-Dependent Manner: A New Model of Takotsubo Cardiomyopathy. Circulation 126, 697-706 (2012).

73. Heubach, J.F., Ravens, U. \& Kaumann, A.J. Epinephrine activates both Gs and Gi pathways, but norepinephrine activates only the Gs pathway through human beta2-adrenoceptors overexpressed in mouse heart. Mol Pharmacol 65, 1313-22 (2004).

74. Heubach, J.F., Blaschke, M., Harding, S.E., Ravens, U. \& Kaumann, A.J. Cardiostimulant and cardiodepressant effects through overexpressed human beta2-adrenoceptors in murine heart: regional differences and functional role of beta1-adrenoceptors. Naunyn Schmiedebergs Arch Pharmacol 367, 380-90 (2003).

75. Chesley, A. et al. The beta(2)-adrenergic receptor delivers an antiapoptotic signal to cardiac myocytes through $\mathrm{G}(\mathrm{i})$-dependent coupling to phosphatidylinositol 3'-kinase. Circ Res 87, 1172-9 (2000).

76. Shao, Y. et al. Novel rat model reveals important roles of betaadrenoreceptors in stress-induced cardiomyopathy. Int J Cardiol 168, 1943-50 (2013).

77. Land, S. et al. Computational modelling of Takotsubo cardiomyopathy: Effect of spatially varying beta-adrenergic stimulation in the rat left ventricle. $\mathrm{Am} \mathrm{J}$ Physiol Heart Circ Physiol (2014).

78. leva, R. et al. Hyper-acute precipitating mechanism of Tako-Tsubo cardiomyopathy: in the beginning was basal hyperkinesis? Int J Cardiol 167, e55-7 (2013).

79. Wright, P.T., Tranter, M.H., Morley-Smith, A.C. \& Lyon, A.R. Pathophysiology of takotsubo syndrome: temporal phases of cardiovascular responses to extreme stress. Circ J 78, 1550-8 (2014).

80. Redfors, B. et al. Different catecholamines induce different patterns of takotsubo-like cardiac dysfunction in an apparently afterload dependent manner. Int J Cardiol 174, 330-6 (2014).

81. Sverrisdottir, Y.B., Schultz, T., Omerovic, E. \& Elam, M. Sympathetic nerve activity in stress-induced cardiomyopathy. Clin Auton Res 22, 259-64 (2012).

82. Redfors, B., Shao, Y., Ali, A. \& Omerovic, E. Are the different patterns of stress-induced (Takotsubo) cardiomyopathy explained by regional mechanical overload and demand: supply mismatch in selected ventricular regions? Med Hypotheses 81, 954-60 (2013).

83. Spinelli, L. et al. L41Q polymorphism of the G protein coupled receptor kinase 5 is associated with left ventricular apical ballooning syndrome. Eur $J$ Heart Fail 12, 13-6 (2010).

84. Liggett, S.B. et al. A GRK5 polymorphism that inhibits beta-adrenergic receptor signaling is protective in heart failure. Nat Med 14, 510-7 (2008).

85. Figtree, G.A. et al. No association of G-protein-coupled receptor kinase 5 or beta-adrenergic receptor polymorphisms with Takotsubo cardiomyopathy in a large Australian cohort. Eur J Heart Fail 15, 730-3 (2013).

86. Kneale, B.J., Chowienczyk, P.J., Brett, S.E., Coltart, D.J. \& Ritter, J.M. Gender differences in sensitivity to adrenergic agonists of forearm resistance vasculature. J Am Coll Cardiol 36, 1233-8 (2000).

87. Patten, R.D. et al. 17beta-estradiol reduces cardiomyocyte apoptosis in vivo and in vitro via activation of phospho-inositide-3 kinase/Akt signaling. Circ Res 95, 692-9 (2004). 
88. Ling, S., Komesaroff, P. \& Sudhir, K. Cellular mechanisms underlying the cardiovascular actions of oestrogens. Clin Sci (Lond) 111, 107-18 (2006).

89. Kam, K.W., Qi, J.S., Chen, M. \& Wong, T.M. Estrogen reduces cardiac injury and expression of beta1-adrenoceptor upon ischemic insult in the rat heart. $J$ Pharmacol Exp Ther 309, 8-15 (2004).

90. Nef, H.M. Abnormalities in intracellular $\mathrm{Ca} 2+$ regulation contribute to the pathomechanism of Tako-Tsubo cardiomyopathy. Eur Heart $J$ In press (2009).

91. Akashi, Y.J., Nef, H.M., Mollmann, H. \& Ueyama, T. Stress cardiomyopathy. Annu Rev Med 61, 271-86 (2010).

92. Sharkey, S.W. \& Maron, B.J. Epidemiology and clinical profile of Takotsubo cardiomyopathy. Circ J 78, 2119-28 (2014).

93. Desmet, W.J., Adriaenssens, B.F. \& Dens, J.A. Apical ballooning of the left ventricle: first series in white patients. Heart 89, 1027-31 (2003).

94. Bybee, K.A. et al. Clinical characteristics and thrombolysis in myocardial infarction frame counts in women with transient left ventricular apical ballooning syndrome. Am J Cardiol 94, 343-6 (2004).

95. Akashi, Y.J. et al. Reversible ventricular dysfunction takotsubo cardiomyopathy. Eur J Heart Fail 7, 1171-6 (2005).

96. Sharkey, S.W. et al. Acute and reversible cardiomyopathy provoked by stress in women from the United States. Circulation 111, 472-9 (2005).

97. Gianni, M. et al. Apical ballooning syndrome or takotsubo cardiomyopathy: a systematic review. Eur Heart J 27, 1523-9 (2006).

98. Hertting, K. et al. Transient left ventricular apical ballooning in a community hospital in Germany. Int J Cardiol 112, 282-8 (2006).

99. Spedicato, L. et al. Transient left ventricular apical ballooning syndrome: a 4year experience. J Cardiovasc Med (Hagerstown) 9, 916-21 (2008).

100. El Mahmoud, R. et al. Prevalence and characteristics of left ventricular outflow tract obstruction in Tako-Tsubo syndrome. Am Heart J 156, 543-8 (2008).

101. Previtali, M., Repetto, A., Panigada, S., Camporotondo, R. \& Tavazzi, L. Left ventricular apical ballooning syndrome: prevalence, clinical characteristics and pathogenetic mechanisms in a European population. Int J Cardiol 134, 91-6 (2009).

102. Eshtehardi, P. et al. Transient apical ballooning syndrome--clinical characteristics, ballooning pattern, and long-term follow-up in a Swiss population. Int J Cardiol 135, 370-5 (2009).

103. Regnante, R.A. et al. Clinical characteristics and four-year outcomes of patients in the Rhode Island Takotsubo Cardiomyopathy Registry. Am J Cardiol 103, 1015-9 (2009).

104. Teh, A.W., New, G. \& Cooke, J. A single-centre report on the characteristics of Tako-tsubo syndrome. Heart Lung Circ 19, 63-70 (2010).

105. Parodi, G. et al. Natural history of tako-tsubo cardiomyopathy. Chest 139, 88792 (2011).

106. Nunez-Gil, I.J. et al. Tako-tsubo syndrome and heart failure: long-term followup. Rev Esp Cardiol (Engl Ed) 65, 996-1002 (2012).

107. Brenner, R. et al. Clinical characteristics, sex hormones, and long-term followup in swiss postmenopausal women presenting with takotsubo cardiomyopathy. Clin Cardiol 35, 340-7 (2012).

108. Samardhi, H. et al. Takotsubo cardiomyopathy: an Australian single centre experience with medium term follow up. Intern Med J 42, 35-42 (2012). 
109. Bellandi, B. et al. [Epidemiology of Tako-tsubo cardiomyopathy: the Tuscany Registry for Tako-tsubo Cardiomyopathy ]. G Ital Cardiol (Rome) 13, 59-66 (2012).

110. Cacciotti, L. et al. Observational study on Takotsubo-like cardiomyopathy: clinical features, diagnosis, prognosis and follow-up. BMJ Open 2 (2012).

111. Sharma, V., Srinivasan, M., Sheehan, D.M. \& Ionescu, A. Stress cardiomyopathy: case series and the review of literature. J Emerg Med 45, e95-8 (2013).

112. Pullara, A. et al. Takotsubo cardiomyopathy: real life management in the intensive coronary care unit. Minerva Med 104, 537-44 (2013).

113. Showkathali, R. \& Ramoutar, A. Takotsubo cardiomyopathy and acute coronary syndrome--overlapping diagnoses will lead to confusion. Eur J Intern Med 25, e78 (2014). 


\section{Figure legends}

Fig.1:(A) Immunohistochemistry of intracellular proteins. a-actinin (specific labelling green, phalloidin red, nuclei blue) was detected only in the border zone of patients with takotsubo syndrome ${ }^{48}$. (B) The extracellular matrix stained with collagen-1 (green) was increased and the myocardial syncytium was separated ${ }^{48}$. (C) Myofibroblasts are detected in takotsubo syndrome confirming the hypothesis of a catecholamine triggered depression of left ventricle. (D) The capillary density stained by CD31 (green) was reduced in patients with Takotsubo syndrome ${ }^{49}$. (E) Most notable, Sarcolipin (red) was present in the left ventricle during the acute phase of takotsubo syndrome contributing to a disturbed regulation of calcium homeostasis ${ }^{90}$. (F) Electron microscopy of biopsies from patients with takotsubo syndrome showing numerous vacuoles of different sizes and contents (myelin bodies, residual cellular products), loss of contractile material, and areas of non-specified cytoplasm. The interstitial space was widened containing formation of cellular debris and contraction bands $\left(^{*}\right)$ of sarcomeres were found ${ }^{48}$. All figures were adapted and modified with permission.

Fig 2: Integrated pathophysiological model for acute takotsubo syndrome. (A) Normal left ventricular systolic performance under normal conditions of perfusion, afterload and $\beta A R$ activation. (B) Acute Takotsubo syndrome triggered by a mixed combination of multivessel vasospasm, transient increased afterload from high aortic and left ventricular endsystolic pressure, followed by subsequent reduction with systemic hypotension, and excessive activation of myocardial $\beta A R s$ with an apical predominance reflecting their high expression. 
Table 1. Diagnostic criteria from the previous report

\begin{tabular}{|c|c|c|c|}
\hline $\begin{array}{l}\text { Mayo Clinic } \\
\text { Criteria, } \\
\text { the U.S. }{ }^{6}\end{array}$ & $\begin{array}{l}\text { Gothenburg } \\
\text { Criteria, } \\
\text { Sweden }^{7}\end{array}$ & $\begin{array}{l}\text { MRI-based Criteria, } \\
\text { Europe and the U.S. }\end{array}$ & $\begin{array}{l}\text { Italian Network } \\
\text { Criteria, } \\
\text { Italy }^{9}\end{array}$ \\
\hline $\begin{array}{l}\text { 1. Transient } \\
\text { akinesis or } \\
\text { dyskinesis of } \\
\text { left ventricular } \\
\text { wall motion } \\
\text { abnormalities } \\
\text { (ballooning) } \\
\text { with chest pain }\end{array}$ & $\begin{array}{l}\text { 1. Transient } \\
\text { hypokinesis, } \\
\text { akinesis, or } \\
\text { dyskinesis in the } \\
\text { left ventricular } \\
\text { segments and } \\
\text { frequently, but not } \\
\text { always, a stressful } \\
\text { trigger (psychical } \\
\text { or physical). }\end{array}$ & $\begin{array}{l}\text { 1. An acute cardiac } \\
\text { event typically } \\
\text { presenting with chest } \\
\text { pain and/or dyspnea }\end{array}$ & $\begin{array}{l}\text { 1. Typical transient } \\
\text { LV wall motion } \\
\text { abnormalities } \\
\text { extending beyond } \\
\text { a single epicardial } \\
\text { vascular } \\
\text { distribution with } \\
\text { complete functional } \\
\text { normalization } \\
\text { within } 6 \text { weeks }\end{array}$ \\
\hline $\begin{array}{l}\text { 2. New } \\
\text { electrocardiogr } \\
\text { aphic changes } \\
\text { (either ST- } \\
\text { elevation or T- } \\
\text { wave } \\
\text { inversion) }\end{array}$ & $\begin{array}{l}\text { 2. The absence of } \\
\text { other pathological } \\
\text { conditions } \\
\text { (e.g. ischemia, } \\
\text { myocarditis, toxic } \\
\text { damage, } \\
\text { tachycardia, etc.) } \\
\text { that may more } \\
\text { credibly explain the } \\
\text { regional } \\
\text { dysfunction. }\end{array}$ & $\begin{array}{l}\text { 2. Transient systolic } \\
\text { dysfunction with } \\
\text { marked LV contraction } \\
\text { abnormality (akinesia } \\
\text { or dyskinesia of the LV } \\
\text { apical and/or } \\
\text { midventricular or basal } \\
\text { segments) }\end{array}$ & $\begin{array}{l}\text { 2. Absence of } \\
\text { potentially culprit } \\
\text { coronary stenosis, } \\
\text { or angiographic } \\
\text { evidence of acute } \\
\text { plaque rupture, } \\
\text { dissection,thrombo } \\
\text { sis or spasm }\end{array}$ \\
\hline $\begin{array}{l}\text { 3. No } \\
\text { significant } \\
\text { obstructive } \\
\text { epicardial } \\
\text { coronary artery } \\
\text { disease }\end{array}$ & $\begin{array}{l}\text { 3. No elevation or } \\
\text { modest elevation in } \\
\text { cardiac troponin } \\
\text { (i.e. disparity } \\
\text { between the } \\
\text { troponin level and } \\
\text { the amount of the } \\
\text { dysfunctional } \\
\text { myocardium } \\
\text { present). }\end{array}$ & $\begin{array}{l}\text { 3. Absence of } \\
\text { significant }(>50 \%) \\
\text { obstructive coronary } \\
\text { artery disease or } \\
\text { angiographic evidence } \\
\text { of acute plaque rupture }\end{array}$ & $\begin{array}{l}\text { 3. New and } \\
\text { dynamic ST- } \\
\text { segment } \\
\text { abnormalities or T- } \\
\text { wave inversion as } \\
\text { well as new onset } \\
\text { of transient or } \\
\text { permanent left } \\
\text { bundle branch } \\
\text { block }\end{array}$ \\
\hline $\begin{array}{l}\text { 4. Absence of } \\
\text { pheochromocyt } \\
\text { oma or } \\
\text { myocarditis }\end{array}$ & & $\begin{array}{l}\text { 4. New } \\
\text { electrocardiographic } \\
\text { abnormalities (either } \\
\text { ST elevation or T-wave } \\
\text { inversion) or modest } \\
\text { elevation in cardiac } \\
\text { troponin level } \\
\text { 5. Absence of } \\
\text { pheochromocytoma }\end{array}$ & $\begin{array}{l}\text { 4. Mild increase in } \\
\text { myocardial injury } \\
\text { markers (creatine } \\
\text { kinase-MB value < } \\
50 \mathrm{U} / \mathrm{L} \text { ) }\end{array}$ \\
\hline
\end{tabular}


6. Absence of myocarditis or typical ischemic transmural late gadolinium enhancement on cardiovascular magnetic resonance (if available).
6. Postmenopausal woman (optional)

7. Antecedent stressful event (optional) 
Table 2. Various stressors (modified from Reference ${ }^{91} 92$ with permission)

\section{Emotional stress}

Anger

Accident

Death or severe illness or injury of a family member, friend, or pet

Earthquake

Financial loss - business, gambling

Involvement with legal proceedings

Move to a new residence

Panic

Public speaking

Receiving bad news - diagnosis of a major illness, one's divorce, spouse leaving for war

Severe argument

Surprise party

\section{Physical stress}

Anemia due to gastrointestinal bleeding

Cocaine use

Drug reaction

Electroconvulsive theraphy

Excessive insulin administration

Noncardiac surgery or procedure - cholecystectomy, hysterectomy, nosebleed treated with phenylephrine

Recovery from general anesthesia

Severe illness - asthma or acute exacerbation of chronic obstructive airway disease, connective tissue disorders, acute cholecystitis, encephalitis, fracture, subarachnoid hemorrhage, pseudomembranous colitis, cancer, endocrine neoplasia, thyrotoxicosis

Severe pain - fracture, renal colic, pneumothorax, pulmonary embolism

Stress test - dobutamine stress echocardiogram, exercise

Suicide attempt

Withdrawal from alcohol, opiate 
Table 3. Recurrence rate from the previous reports (modified from Reference ${ }^{46}$ with permission)

\begin{tabular}{|c|c|c|c|c|}
\hline Authors & Country & $\begin{array}{l}\text { Reported } \\
\text { year }\end{array}$ & $\begin{array}{l}\text { Recurrence } \\
\text { cases/ all } \\
\text { subjects }\end{array}$ & $\begin{array}{l}\text { Recurrence } \\
\text { rate }(\%)\end{array}$ \\
\hline Tsuchihashi, et al. ${ }^{59}$ & Japan & 2001 & $2 / 72$ & 2.8 \\
\hline Desmet, et al. ${ }^{93}$ & Belgium & 2003 & $1 / 13$ & 7.7 \\
\hline Bybee, et al. ${ }^{94}$ & U.S.A & 2004 & $1 / 16$ & 6.2 \\
\hline Akashi, et al. ${ }^{95}$ & Japan & 2005 & $0 / 13$ & 0 \\
\hline Sharkey, et al. ${ }^{96}$ & U.S.A & 2005 & $1 / 11$ & 9.1 \\
\hline Gianni, et al. ${ }^{97}$ & Italy, Canada & 2006 & $6 / 169$ & 3.5 \\
\hline Hertting, et al. ${ }^{98}$ & Germany & 2006 & $0 / 32$ & 0 \\
\hline Kurowski, et al. ${ }^{11}$ & Germany & 2007 & $2 / 35$ & 5.7 \\
\hline Elesber, et al. ${ }^{31}$ & U.S.A & 2007 & $10 / 100$ & 11.4 \\
\hline Spedicato, et al. ${ }^{99}$ & Italy & 2008 & $2 / 29$ & 6.9 \\
\hline El Mahmound, et al. ${ }^{100}$ & France & 2008 & $0 / 32$ & 0 \\
\hline Previtali, et al. ${ }^{101}$ & Italy & 2009 & $1 / 18$ & 5.6 \\
\hline Eshtehardi, et al. ${ }^{102}$ & Switzerland & 2009 & $2 / 41$ & 4.9 \\
\hline Regnante, et al. 103 & U.S.A & 2009 & $2 / 70$ & 2.9 \\
\hline Teh, et al. ${ }^{104}$ & Australia & 2010 & $0 / 23$ & 0 \\
\hline Primetshofer, et al. ${ }^{13}$ & Austria & 2010 & $1 / 31$ & 3.2 \\
\hline Sharkey, et al. ${ }^{32}$ & U.S.A & 2010 & $7 / 136$ & 5.1 \\
\hline Song, et al. ${ }^{34}$ & Korea & 2010 & $0 / 87$ & 0 \\
\hline Parodi, et al. ${ }^{105}$ & Italy & 2011 & $2 / 116$ & 1.7 \\
\hline Nunez-Gil, et al. 106 & Spain & 2012 & $4 / 100$ & 4.0 \\
\hline Brenner, et al. ${ }^{10 /}$ & Switzerland & 2012 & $2 / 17$ & 11.7 \\
\hline Samardhi, et al. ${ }^{108}$ & Australia & 2012 & $0 / 51$ & 0 \\
\hline Bellandi, et al. ${ }^{109}$ & Italy & 2012 & $0 / 105$ & 0 \\
\hline Cacciotti, et al. ${ }^{110}$ & Italy & 2012 & $1 / 75$ & 1.3 \\
\hline Vriz, et al. ${ }^{42}$ & Italy & 2013 & $5 / 23$ & 21.7 \\
\hline Sharma, et al. ${ }^{111}$ & U.K. & 2013 & $0 / 12$ & 0 \\
\hline Pullara, et al. ${ }^{112}$ & Italy & 2013 & $2 / 26$ & 7.7 \\
\hline Patel, et al. ${ }^{14}$ & U.S.A & 2013 & $7 / 224$ & 3.1 \\
\hline Showkathali, et al. ${ }^{113}$ & U.K. & 2014 & $0 / 17$ & 0 \\
\hline Murakami, et al. ${ }^{15}$ & Japan & 2014 & $9 / 107$ & 4.7 \\
\hline Nishida, et al. ${ }^{28}$ & Japan & 2014 & $7 / 251$ & 2.8 \\
\hline Sum and average & & & $77 / 2052$ & 3.8 \\
\hline
\end{tabular}



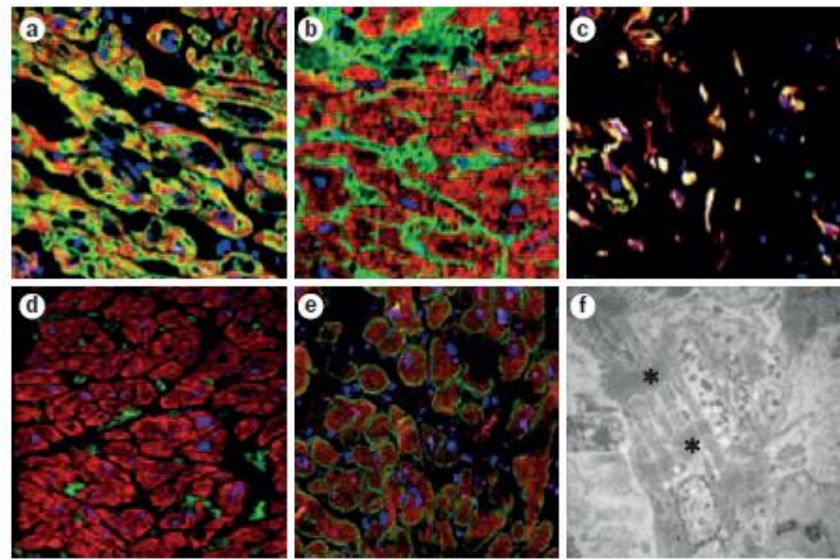

Figure 1 | Histopathological features of Takotsubo syndrome.

a | Immunohistochemistry of intracellular proteins shows $a$-actinin (specific labelling green, phalloidin red, nuclei blue) only in the border zone..$^{49} \mathbf{b}$ | The extracellular matrix shows increased concentrations of collagen type I and the myocardial syncytium is separated. ${ }^{49} \mathbf{c}$ | Myofibroblasts are present, which confirms the hypothesis of a catecholamine-triggered depression of left ventriclar function. d | Capillary density is reduced (stained by CD 31 , green). ${ }^{50} \mathrm{e} \mid$ Sarcolipin, shown in red, is present in the left ventricle during the acute phase of Takotsubo syndrome, and contributes to disturbed regulation of calcium homeostasis. ${ }^{91} \mathbf{f} \mid$ The myocardium contains numerous vacuoles of varying size and contents (myelin bodies and residual cellular products), loss of contractile material, and areas of nonspecified cytoplasm. The asterisk indicates interstitial space widened owing to formation of cellular debris and contraction bands of sarcomeres. ${ }^{49}$ Permission for Figure 1a, b, and fobtained from Oxford University Press @ㅇNㅇ, H. M. et al. Takotsubo cardiomyopathy: intraindividual structural analysis in the acute phase and after functional recovery. Eur. Heart J. 28, 2456-2464 (2007). Permission for Figure 10 obtained from Elsevier (c) Szardien, S. et al. Molecular basis of disturbed extracellular matrix homeostasis in stress cardiomyopathy. Int. J. Cardio. 168, 1685-1688

(2013). Permission for Figure 1e obtained from Oxford University Press @ Nef, H. M. et al. Abnormalities in intracellular $\mathrm{Ca}^{2+}$ regulation contribute to the pathomechanism of Tako-Tsubo cardiomyopathy. Eur. Heart J. 30, 2155-2164 (2009). 

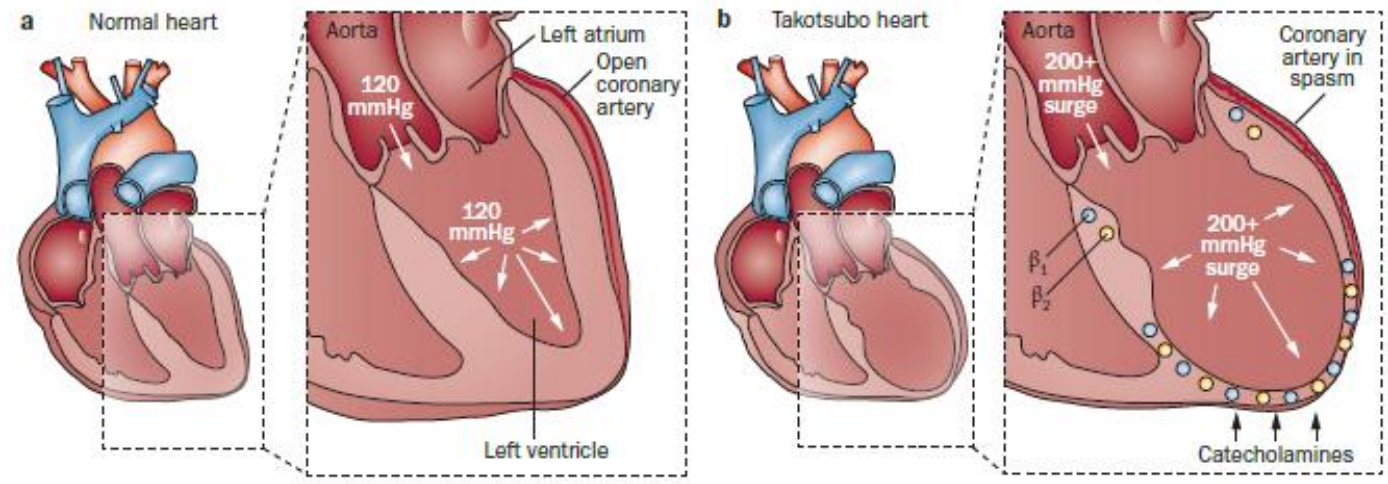

Figure 2 | Integrated pathophysiological model for acute apical dysfunction in Takotsubo syndrome. a | Left ventricular systolic performance under normal conditions of perfusion, afterload, and $\beta$-adrenoceptor activation. b | The acute phase of Takotsubo syndrome can be characterized by peripheral arterial vasospasm leading to increased afterload and transient high left ventricular end-systolic pressure, acute coronary artery vasospasm causing myocardial ischaemia, and a subsequent reduction in cardiac output with systemic hypotension and direct catecholamine-mediated myocardial stunning in the apex where the $\beta$-adrenoceptor gradient is highest. 